Review Article

\title{
Academic Insights and Perspectives: Cellular Automata and Production Scheduling
}

\author{
Yong Chen, Feiyang Yu, Ziwen Cheng, Qiuxia Jin, Zhi Pei, and Wenchao Yi iD \\ College of Mechanical Engineering, Zhejiang University of Technology, Hangzhou 310012, China \\ Correspondence should be addressed to Wenchao Yi; yiwenchao@zjut.edu.cn
}

Received 23 December 2019; Revised 31 May 2020; Accepted 7 July 2020; Published 6 August 2020

Academic Editor: Purushothaman Damodaran

Copyright (c) 2020 Yong Chen et al. This is an open access article distributed under the Creative Commons Attribution License, which permits unrestricted use, distribution, and reproduction in any medium, provided the original work is properly cited.

The cellular automata algorithm is one of the most important developments recently and is becoming an area of great potential in scheduling problems. There has been an increase in the quality and quantity of publications related to this topic. To formally illustrate the research status of the cellular automata algorithm at the global level, bibliometric analysis was used based on the Web of Science and Scopus databases, and 3086 documents were retrieved from different countries and regions. Institutions, journals, authors, research areas, author keywords, and highly cited articles are discussed in detail. The results show that the USA and China are the dominant countries in this field. The USA is the most active country cooperating with other 47 countries or regions, especially with China. The Journal of Cellular Automata is the most productive journal in this field, and the Democritus University of Thrace is the most productive institution also with the highest h-index. "Computer Science" is the most investigated area, with 544 documents involved. In addition, the major topics focused by author keywords are "genetic algorithm," "swarm intelligence," and "evolutionary computation." In addition, the cellular automata algorithm is viewed as a new and effective method to solve the scheduling problems in manufacturing system; meanwhile, historical developments of the application of cellular automata in scheduling are displayed and analyzed.

\section{Introduction}

In recent years, the cellular automata algorithm has become one of the fastest-growing technologies in complex systems, and its rise in academia suggests the potential to be an important role in various aspects. According to a survey of the literature, cellular automata stem from computer areas. In the 1950s, the father of the computer John Von Neumann, one of the earliest scientists who fully realized the relationships between life and computing, proposed that replication was a unique feature of living objects and created a cellular automaton that successfully solved the machine selfreplication problem [1]. Von Neumann was a pioneer in artificial life sciences, and after that, the construction of machines with vital features created by cellular automata has become a new direction of scientific research. Many scholars have begun to pay attention to the research of cellular automata and its algorithms. In the 1970s, the Cambridge University mathematician John Horton Conway created the
"Life Game," a cellular automaton model with the ability to generate dynamic patterns and dynamic structures, which demonstrated how complex things (even life) evolved from the simplest rules, and promoted the rapid development of cellular automata research [2]. In the 1980s, the famous mathematician and physicist Stephen Wolfram conducted detailed and deep research on all models produced by the 256 rules of elementary cellular automata. He used entropy to describe its evolutionary behavior and divided cellular automata into four categories: stationary, periodic, chaotic, and complex [3]. With the progress of complex research, the cellular automata approach, as an effective tool for exploring complex systems, has gained in-depth research and extensive applications.

Since emerging, cellular automata have been widely used in various fields of social, economic, military, and scientific research. Applications include sociology, biology, ecology, information science, computer science, mathematics, physics, chemistry, geography, dilemma, and military 
science. In sociology, cellular automata algorithms are used to study the formation and outbreak of economic crises, the social nature of individual behavior, and popular phenomena, such as the formation of fashion colors [4-9]. In biology, the design idea of cellular automata itself comes from the idea of biological self-propagation, so its biological application is more natural and extensive. For example, cellular automata were used in HIV infection studies [10], self-organization, self-research on life phenomena such as reproduction and research on clone technology [11], human brain mechanism exploration [12], and tumor cell growth mechanism and process simulation [13]. In ecology, the cellular automaton is used to simulate the dynamic process of population changes of animals, plants, and other living organisms [14-18], as well as the simulation of the behavior of groups of animals such as ants [19] and geese [20]. With reference to computer science, cellular automata can be viewed as a parallel computer for parallel computing research [21-24]. In addition to the successful application of lattice gas cellular automata in fluid mechanics, the cellular automaton is also applied to the simulation of fields such as magnetic fields [25] and electric fields [26], as well as the simulation of thermal diffusion [27], heat conduction [28], and mechanical waves [29]. In environmental science, cellular automata were used to simulate the simulation of oil pollution after oil spills [30], wastewater around a factory [31], and diffusion of exhaust gases [32].

These reviews above were organized in terms of technical content and we would like to present a different perspective by using bibliometric analysis to show the historical map and overall view of the cellular automata research field. Bibliometric analysis is quite effective for analyzing scientific publications to map the historical development of the target topic, find hotspots, and highlight distribution layout of active researching countries, institutions, authors, and their cooperation relations, as well as top journal, leading publications, and research trends [33]. Bibliometric analysis has been applied successfully in the area of laser processing technology in 2020 and more effective ways are considered in this paper [34].

\section{Material and Methods}

2.1. Data Source and Search Strategy. In our study, bibliometric analyses were carried out based on employing the Web of Science core collection database and Scopus database, which we used to retrieve documents related to the cellular automata algorithm. The Web of Science database and Scopus database are widely deemed as the most useful tools to generate citation data for scientific research and also are effective sources of high-quality papers [35].

All the WoS core collection of the three Citation Indexes, namely, Science Citation Index Expanded (SCIE), Social Science Citation Index (SSCI), and Art and Humanity Citation Index (A HCI), has collected more than 12,000 authoritative $[36,37]$ and high-impact academic journals in the world, including natural science, engineering, biomedicine, social sciences, art, and humanities [38-40]. And more than 20,000 academic journals are collected in Scopus database.
The literature was retrieved on April 30, 2020, and the document types (article and review) were considered in our study, while other document types, such as book chapter, news item, and editorial material, were eliminated. The years of publication span from 1984 to 2020.

2.2. Research Methods. The following search expressions in the WoS and Scopus databases advance search were used in the title, abstract, and keywords to obtain the research output at the global level: cellular automata, cellular automata simulation, and cellular automata algorithm. Thus, the search queries in WoS and Scopus were as follows: TS $=$ ("Cellular automata") and TS $=\left(\right.$ algorithm $\left.{ }^{*}\right)$, TITLEABS-KEY (cellular AND automata) AND TITLE-ABS-KEY $\left(\right.$ algorithm ${ }^{*}$ ), respectively, and document types were refined to article and review. As a result, 3086 documents were collected.

To illustrate the study trends and milestones of cellular automata algorithm research, several bibliometric indicators were analyzed [40-42], such as the global contributions and the leading countries/regions, productive journals, institutions, research areas, h-index, and impact factors. Some analysis tools, such as bubble charts, cross-relationship maps, and tables, were also employed [43, 44].

\section{Results and Discussions}

3.1. Global Contribution and Leading Countries/Regions. The resulting sample based on our analysis comprises 3086 documents, including 2921 articles and 165 reviews, with 82 countries or regions contributing to the cellular automata algorithm field. The yearly average was 85 documents. As shown in Figure 1, there has been a slow and steady growth trend in the amount of literature on cellular automata algorithm during the period from 1984 to 2020. The first article was published in Microprocessing and Microprogramming by Michel Meriaux in 1984. This paper adjusted some fundamental algorithms to build a cellular machine to solve some problems in image synthesis. Table 1 shows the top 20 countries and regions in terms of the number of publications related to cellular automata algorithm. The country with the highest scientific research output globally was China with a total of $723(23.42 \%)$ articles since 1996, followed by the USA $(455,14.7 \%)$ and Japan $(190,6.16 \%)$. This implies that cellular automata algorithm has attracted worldwide researchers in sharing ideas and in cooperating with each other.

Figure 2 shows the number of articles per year in the top 20 countries and regions. During the period from 1984 to 1996, only a small number of articles were published each year; however, this field witnessed explosive growth in publications from 1997 and this is a continuing trend. France, Canada, Greece, Germany, the USA, and China are the earliest countries to publish papers about cellular automata algorithm in the top 20. The USA has had a steady number of publications each year and has been maintaining this growth for almost 3 decades. One observation is that China has a much higher annual output of publications in 


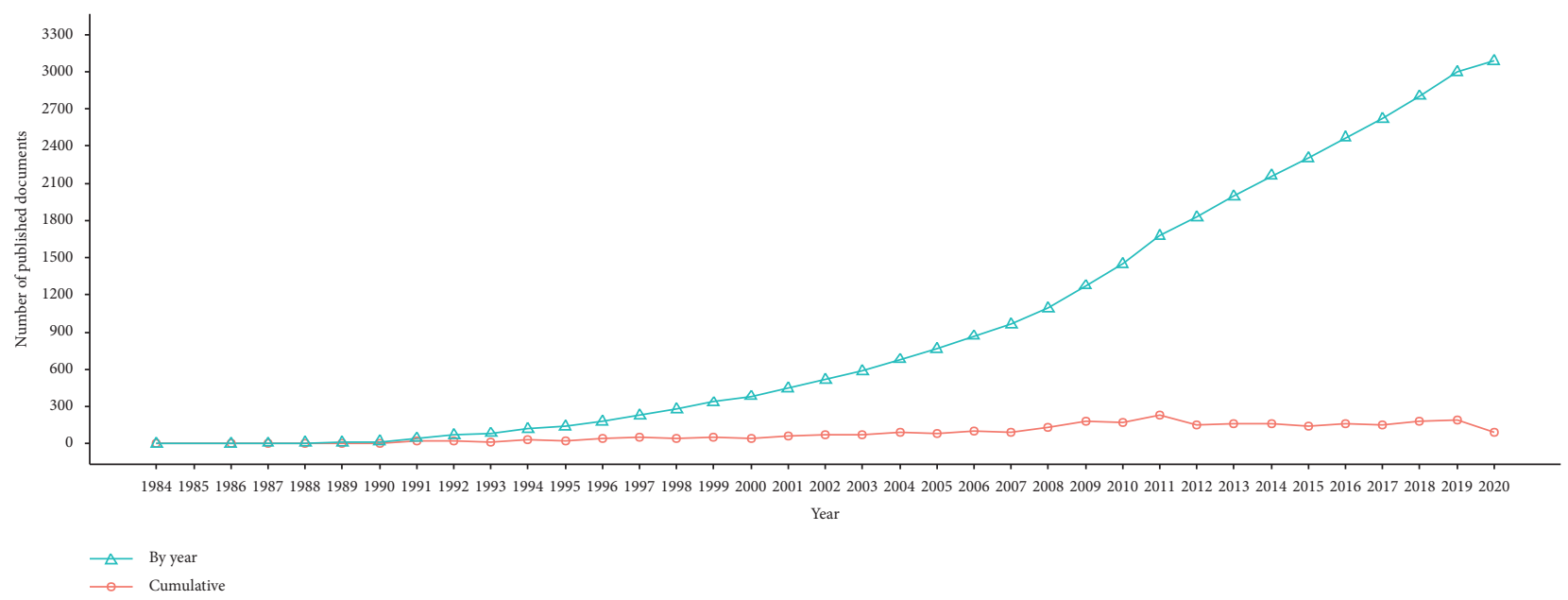

FIgURE 1: Number of published documents from the global related to cellular automata algorithm.

TABle 1: The top 20 productive countries and regions in cellular automata algorithm during 1984-2020.

\begin{tabular}{lccccc}
\hline Rank & Country/region & TA & TC & ACPP & NCC \\
\hline 1 & China & 722 & 9624 & 13.33 & 30 \\
2 & USA & 455 & 19708 & 43.31 & 47 \\
3 & Japan & 190 & 2393 & 12.59 & 24 \\
4 & India & 187 & 3607 & 19.29 & 14 \\
5 & United Kingdom & 185 & 5614 & 30.35 & 33 \\
6 & Iran & 173 & 2256 & 13.04 & 22 \\
7 & France & 161 & 2180 & 13.54 & 30 \\
8 & Italy & 158 & 2700 & 17.09 & 26 \\
9 & Germany & 136 & 4402 & 32.37 & 26 \\
10 & Spain & 96 & 2709 & 28.22 & 15 \\
11 & Canada & 95 & 1932 & 20.34 & 25 \\
12 & Poland & 86 & 658 & 7.65 & 21 \\
13 & Australia & 84 & 2190 & 26.07 & 14 \\
14 & Greece & 80 & 1784 & 22.30 & 21 \\
15 & Brazil & 76 & 1366 & 17.97 & 14 \\
16 & Turkey & 72 & 4353 & 60.46 & 5 \\
17 & South Korea & 56 & 576 & 10.29 & 5 \\
18 & Switzerland & 56 & 2181 & 38.95 & 12 \\
19 & Taiwan & 48 & 1408 & 29.33 & 4 \\
20 & Netherlands & 46 & 2368 & 51.48 & 16 \\
\hline
\end{tabular}

TA: total articles; TC: total citations; ACPP: average citations per publication; NCC: number of cooperative countries or regions.

the recent 10 years, especially in 2011, despite few publications in the initial 10 years. Iran is the latest to publish cellular automata algorithm-related articles but is still in the sixth position because of the high output in the recent 5 years. The remaining countries and regions of the top 20 had similar distributions of the annual number of publications, with a steady and relatively large number of publications per year, indicating that this research area is a hotspot around the world.

To illustrate the relationships of the top 20 productive countries and regions, a cross-relationship map is employed in this paper, as shown in Figure 3. The size of the nodes is proportional to the total number of publications, the lines represent links between areas, and the thicker the line is, the stronger the link is. Though China has the largest number of publications, the USA should be viewed as the dominant country which has collaborations with other 47 countries and regions, and American researchers have contributed in field of cellular automata for a long time from 1988. And China is the second dominant country because of its leading position in number of publications and the third position in number of cooperative countries or regions. Nowadays, China pays great attention to the cooperation with other countries and shows a prosperous trend in this field in recent years. There is no doubt that the influence of China will further strengthen in the future.

3.2. Contribution of Leading Research Areas. As is well known, the cellular automata algorithm is currently one of the most popular algorithms in the world, which is supported by 3086 papers distributed in 140 research areas. Table 2 displays the ranking of the top 20 prevalent areas of interest in cellular automata algorithm research. The most published documents were in the field of "Computer Science" (544 documents, $17.55 \%$ ), and China contributed the most papers in this field with 215 documents, accounting for $39.52 \%$ in total 544 articles in "Computer Science." "Engineering" $(418,13.49 \%)$ followed the "Computer Science" in terms of the total number of articles. China has the highest contributions in the first two areas, and the USA is the second one. However, many areas conclude "Computer Science," such as "Computer Science, Theory and Methods," "Computer Science, Artificial Intelligence," and "Computer Science, Interdisciplinary Applications," respectively, which indicates the leading position of "Computer Science" in this field. "Metallurgy and Metallurgical Engineering," "Materials Science, Multidisciplinary," and "Mathematics" lead the list in terms of average citations per publication (ACPP), with values of $28.43,20.77$, and 20.71 , respectively. The most active countries in 19 research areas among top 20 are the USA and China. Iran has the highest contributions in "Computer Science, Artificial Intelligence."

Figure 4 shows the number of articles per year in the top 20 most prevalent research areas. The first cellular automata algorithm-related article, belonging to "Computer Science" 


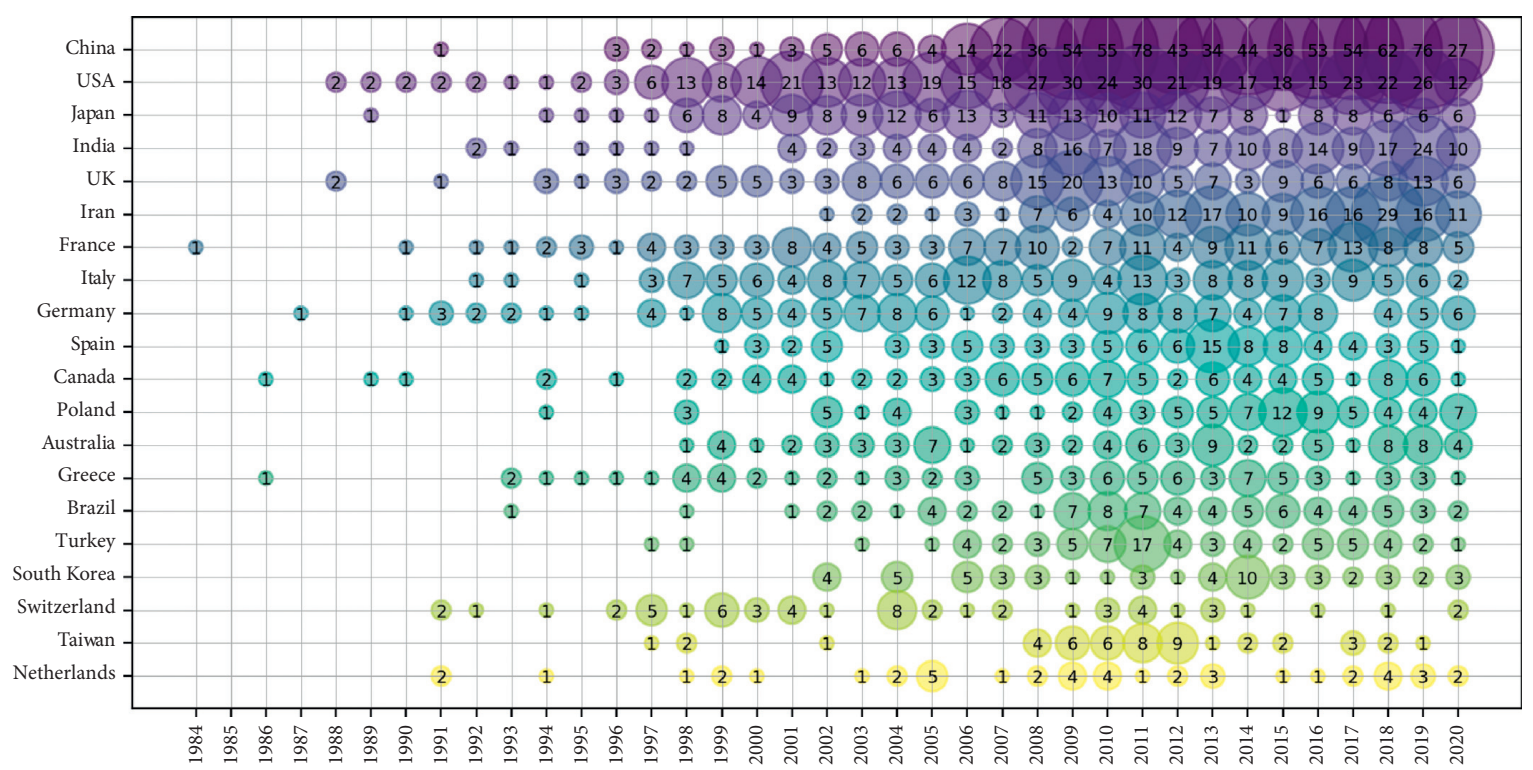

Figure 2: The bubble chart of top 20 productive countries/regions by year during 1984-2020.

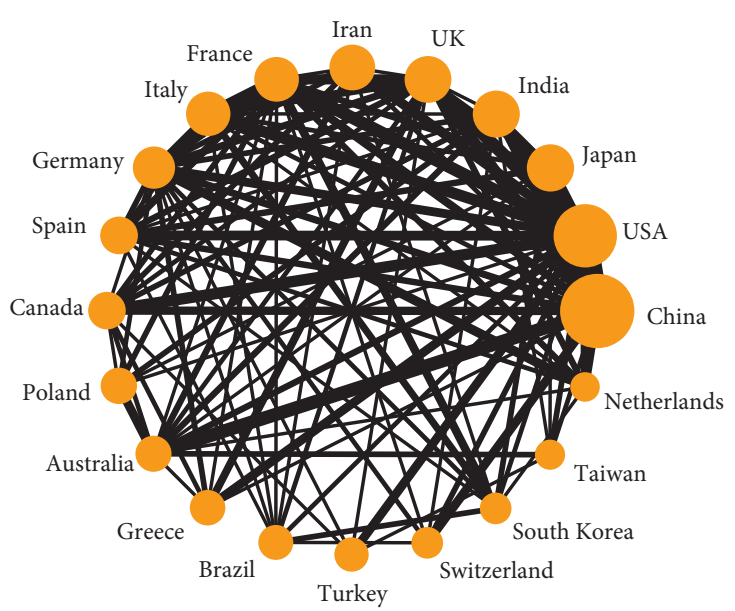

FIgURE 3: The cross-relationship map of the top 20 productive countries/regions.

area, was published in 1999 by van Loocke, Philip R. However, an article named "Massively Parallel Computation of Computation of Conservation-Laws" published in "Computer Science, Theory and Methods" area by Garbey and Levine in 1990 is much earlier. For "Computer Science" area, there is a fluctuating trend: there were few and an unsteady number of publications during 1984-1995, after which, two significant phases with quick growth were witnessed from 1996 to 2001 and from 2007 to 2012, with more than 20 articles per year. The development trends of other areas related to "Computer Science" like "Computer Science, Interdisciplinary Applications" and "Computer Science, Artificial Intelligence" were similar to "Computer Science" area. Besides "Computer Science," the applications of cellular automata algorithm in "Engineering" and "Mathematics" also have significant growth phases and the number of published documents increased sharply in 2007. As for other areas, the applications maintained a relatively stable development rate and had a significant increase in recent 6-8 years. From the overall perspective of development, it can be seen that the period from 2010 to 2020 has a rapid development for the applications of cellular automata algorithms in various areas.

The cross-relationship map of top 20 research areas is shown in Figure 5. "Computer Science" area is the hottest area. Among the 20 areas, 7 areas include "Computer Science" and are related to other 13 areas tightly. After "Computer Science," "Mathematical" is also a hot area with great connected relationships with "Physics," "Engineering," "Materials," and "Geography." From that, it can be concluded that the applications of cellular automata algorithms are multidisciplinary, especially with "Computer Science" and "Mathematical."

3.3. Contribution of Leading Journals. For scholars who are working in the cellular automata algorithm field or people involved in it, it is significant to identify journals that publish papers related to the cellular automata algorithm and find a suitable one to be considered when performing a literature review. In this study, there are 723 journals that contribute to cellular automata algorithm literature, and the top 20 most productive journals are shown in Table 3. Journal of Cellular Automata was the most comprehensive source of automata algorithm $(62,2.01 \%)$ with an average of 3.06 citations per publication and it was mostly considered by researchers from France, followed by Cellular Automata, Proceedings $(50,1.62 \%)$ with an average of 6.44 citations per publication, and was mostly used by researchers from Italy and Japan. International Journal of Modern Physics C (39, 1.26\%), with an average of 7.18 citations per publication, was mostly used by researchers from Turkey. The top 20 journals listed in Table 3 have covered 562 articles with the share of $18.21 \%$. In terms of influence factor (IF), IEEE Transactions on Evolutionary Computation has the highest value of 10.364; it is 
TABLE 2: The top 20 prevalent research areas in cellular automata algorithm during 1984-2020.

\begin{tabular}{|c|c|c|c|c|c|c|c|}
\hline Rank & Research area & TA & TC & ACPP & TPR (\%) & Most active country & Number of documents (\%) \\
\hline 1 & Computer Science & 544 & 10665 & 19.60 & 17.55 & China & $215(39.52 \%)$ \\
\hline 2 & Engineering & 418 & 6034 & 14.44 & 13.49 & China & $155(37.08 \%)$ \\
\hline 3 & Computer Science, Theory and Methods & 398 & 2569 & 6.45 & 12.84 & USA & $36(9.05 \%)$ \\
\hline 4 & Mathematics & 283 & 5862 & 20.71 & 9.13 & USA & $86(30.39 \%)$ \\
\hline 5 & Computer Science, Artificial Intelligence & 281 & 1181 & 4.20 & 9.07 & Iran & $29(10.32 \%)$ \\
\hline 6 & $\begin{array}{c}\text { Computer Science, Interdisciplinary } \\
\text { Applications }\end{array}$ & 276 & 1634 & 5.92 & 8.91 & USA & $26(9.42 \%)$ \\
\hline 7 & Engineering, Electrical and Electronic & 262 & 1932 & 7.37 & 8.45 & USA & $32(12.21 \%)$ \\
\hline 8 & Physics, Mathematical & 178 & 2585 & 14.52 & 5.74 & USA & $31(17.42 \%)$ \\
\hline 9 & Materials Science, Multidisciplinary & 153 & 3178 & 20.77 & 4.94 & China & $31(20.26 \%)$ \\
\hline 10 & Computer Science, Information Systems & 149 & 861 & 5.78 & 4.81 & China & $24(16.11 \%)$ \\
\hline 11 & Mathematics, Interdisciplinary Applications & 144 & 559 & 3.88 & 4.65 & USA & $15(10.42 \%)$ \\
\hline 12 & Physics, Multidisciplinary & 142 & 2343 & 16.50 & 4.58 & USA & $17(11.97 \%)$ \\
\hline 13 & Mathematics, Applied & 133 & 1349 & 10.14 & 4.29 & USA & $14(10.53 \%)$ \\
\hline 14 & Computer Science, Software Engineering & 113 & 513 & 4.54 & 3.65 & USA & $11(9.73 \%)$ \\
\hline 15 & Computer Science, Hardware and Architecture & 103 & 643 & 6.24 & 3.32 & USA & $11(10.68 \%)$ \\
\hline 16 & Physics, Applied & 87 & 1107 & 12.72 & 2.81 & USA & $10(11.49 \%)$ \\
\hline 17 & Engineering, Multidisciplinary & 76 & 306 & 4.03 & 2.45 & China & $9(11.84 \%)$ \\
\hline 18 & Geography, Physical & 72 & 1231 & 17.10 & 2.32 & China & $23(31.94 \%)$ \\
\hline 19 & Metallurgy and Metallurgical Engineering & 72 & 2047 & 28.43 & 2.32 & China & $20(27.78 \%)$ \\
\hline 20 & Geography & 72 & 1019 & 14.15 & 2.32 & China & $24(33.33 \%)$ \\
\hline
\end{tabular}

TA: total articles; TC: total citations; ACPP: average citations per publication; TPR\%: the percentage of articles of areas in total articles.

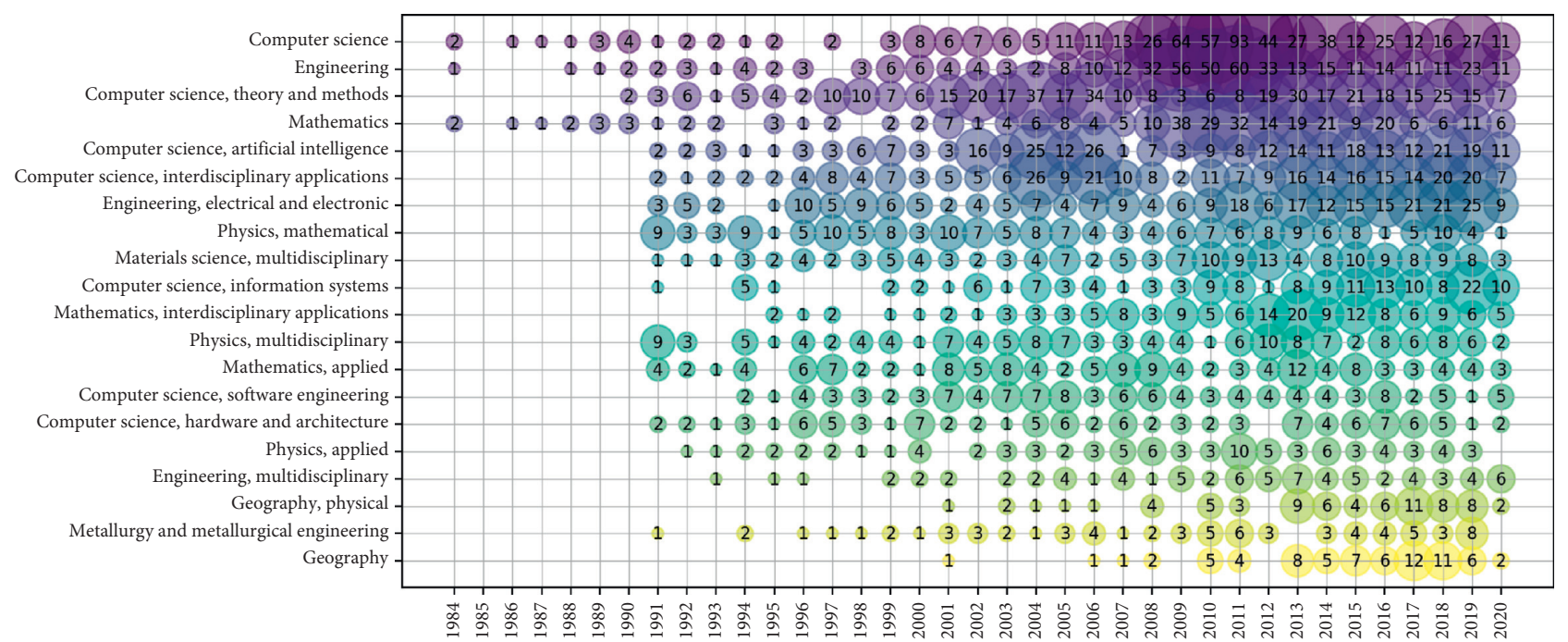

Figure 4: The bubble chart of top 20 most prevalent research areas in cellular automata algorithm by year.

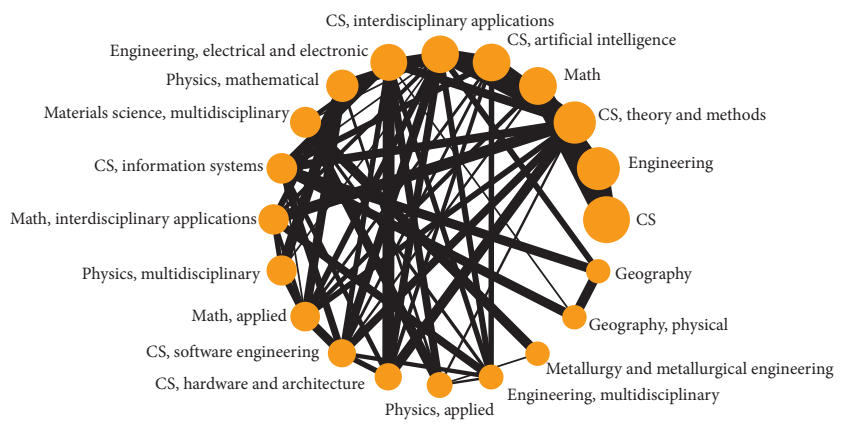

Figure 5: The cross-relationship map of top 20 most prevalent research areas in cellular automata algorithm. followed by information sciences and expert systems with applications with values of 5.305 and 4.577, respectively. Apart from it, their total citations are 2373, 1421, and 1628, respectively, which exceed other journals far.

To illustrate the historical map of cellular automata algorithm-related publications in journals, the bubble char of top 20 productive journals by year is shown in Figure 6 . There were few cellular automata algorithm-related articles distributed in the top 20 journals during the period of 1984 to 2001 , by which time researchers had mainly focused on statistical physics, mathematical, computer science, and ecological modeling. After 2003, the cellular automata algorithm-related areas saw a significant rise in publications, especially after 2006. The cellular automata-oriented journal, 
TABLE 3: The top 20 prevalent journals in cellular automata algorithm during 1984-2020.

\begin{tabular}{|c|c|c|c|c|c|c|}
\hline Rank & Journal & TA & TC & ACPP & TRP\% & IF \\
\hline 1 & Journal of Cellular Automata & 62 & 190 & 3.06 & 2.01 & 0.789 \\
\hline 2 & Cellular Automata, Proceedings & 50 & 322 & 6.44 & 1.62 & 0.402 \\
\hline 3 & International Journal of Modern Physics C & 39 & 280 & 7.18 & 1.26 & 1.116 \\
\hline 4 & International Journal of Geographical Information Science & 39 & 980 & 25.13 & 1.26 & 3.497 \\
\hline 5 & Information Sciences & 31 & 1421 & 45.84 & 1.00 & 5.305 \\
\hline 6 & Theoretical Computer Science & 31 & 414 & 13.35 & 1.00 & 0.791 \\
\hline 7 & Expert Systems with Applications & 30 & 1628 & 54.27 & 0.97 & 4.577 \\
\hline 8 & Natural Computing & 26 & 102 & 3.92 & 0.84 & 1.298 \\
\hline 9 & Lecture Notes in Computer Science & 26 & 71 & 2.73 & 0.84 & $\mathrm{n} / \mathrm{a}$ \\
\hline 10 & Computational Materials Science & 25 & 550 & 22.00 & 0.81 & 2.668 \\
\hline 11 & Fundamenta Informaticae & 25 & 278 & 11.12 & 0.81 & 0.83 \\
\hline 12 & Physica A: Statistical Mechanics and its Applications & 23 & 236 & 10.26 & 0.75 & 2.464 \\
\hline 13 & Journal of Statistical Physics & 22 & 428 & 19.45 & 0.71 & 1.62 \\
\hline 14 & Physical Review e & 22 & 783 & 35.59 & 0.71 & 2.38 \\
\hline 15 & Biosystems & 20 & 423 & 21.15 & 0.65 & 1.593 \\
\hline 16 & Modeling and Simulation in Materials Science and Engineering & 20 & 593 & 29.65 & 0.65 & 2.19 \\
\hline 17 & Journal of Supercomputing & 19 & 144 & 7.58 & 0.62 & 1.943 \\
\hline 18 & Applied Mathematics and Computation & 18 & 536 & 29.78 & 0.58 & 2.429 \\
\hline 19 & Journal of Computational Science & 17 & 72 & 4.24 & 0.55 & 2.347 \\
\hline 20 & IEEE Transactions on Evolutionary Computation & 17 & 2373 & 139.59 & 0.55 & 10.364 \\
\hline
\end{tabular}

TA: total articles; TC: total citations; ACPP: average citations per publication; TPR\%: the percentage of articles of areas in total articles; IF: influence factor.

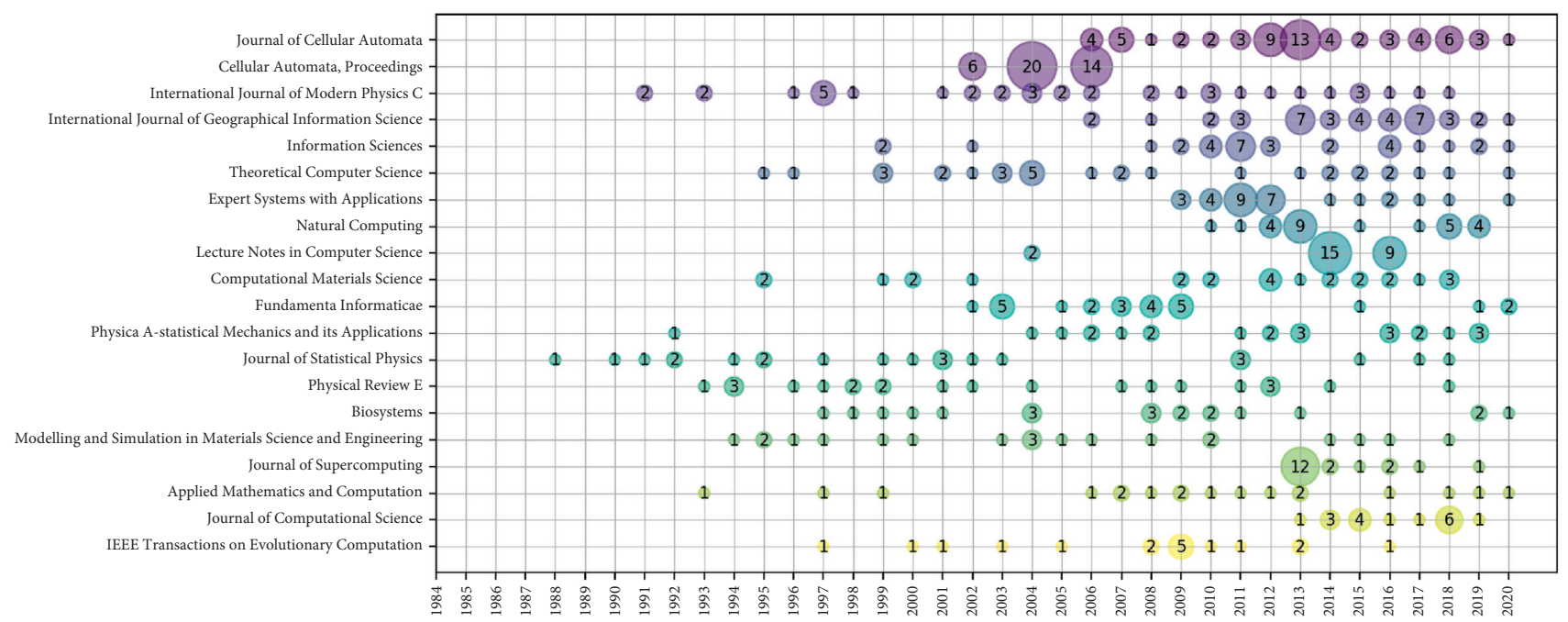

FIGURE 6: The bubble chart of top 20 most prevalent journals in cellular automata algorithm by year.

Journal of Cellular Automata, was launched in 2006 and immediately hold the first position in terms of the total number of publications. Apart from it, the top journals contributing to this increasing trend are International Journal of Geographical Information Science, Expert Systems with Applications, Natural Computing, Computational Materials Science, and so on which indicate that the deep interests and close attention are in the fields of geographical science, materials science, computer science, and engineering optimization.

3.4. Analysis of Author Keywords. To reveal the main focus and research trend of the cellular automata algorithm studies, 4867 author keywords from the retrieved results are analyzed, which indicates a wide range of interests in the cellular automata algorithm. Top 20 author keywords by year are shown in Figure 7. In this study, "cellular automata," the topic of our article, had been used for 1280 times in total and increased sharply in 1996. In 2006, which is year when Journal of Cellular Automata was launched, the citation number of "cellular automata" increased simultaneously. Except "cellular automata," "genetic algorithm" is the most frequently used keywords (185 times), followed by "swarm intelligence" (178) and "particle swarm optimization" (121), which were three main ways of interaction with cellular automata. However, the researches related to swarm intelligence or optimization in recent year are less than them during 2007 to 2013. As for the application area, "evolutionary computation," "image encryption," "parallel 


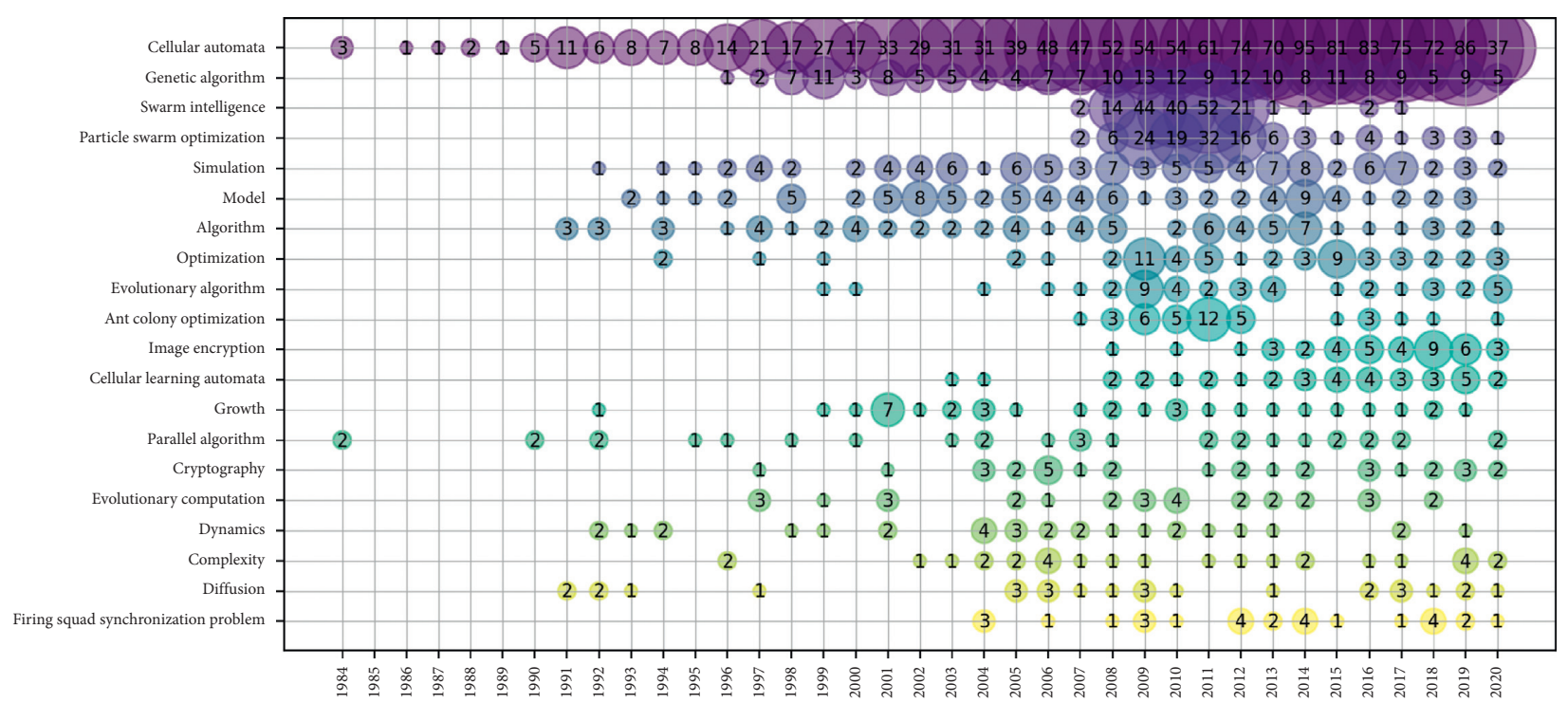

Figure 7: Bubble chart of top 20 author keywords in cellular automata algorithm by year.

computing," and so on emerge early and maintain a low and stable output almost every year. By contrast, some keywords related to algorithms and optimization, like "evolutionary algorithm" and "ant colony optimization," witnessed explosive growth in 2008. It indicts a new trend about the application of cellular automata, and researchers prefer to build a cellular automata model and combine this model with intelligent algorithms.

Figure 8 shows the relationships of the top 20 author keywords in cellular automata algorithm. "Cellular automata" has relationships with all other 19 keywords, especially with "genetic algorithm." Apart from it, some other author keywords related to algorithm, like "ant colony optimization," "evolutionary computation," and so on, have relationships with at least 4 keywords. On the other side, "image encryption" and "cryptography," which belong to cryptography area, have weak relationships with other keywords, except with "cellular automata." From that, it is known that the relationships mentioned above were all based on relationships with "cellular automata," which showed that the "cellular automata algorithm" has become a new multidisciplinary field.

3.5. Contribution of Leading Institutions. Table 4 shows the top 20 institutions in cellular automata algorithm in terms of their total number of publications, citations, and h-index. Apparently, all the 20 institutions were from the 20 most productive countries. Democritus University of Thrace, which belongs to Greece, leads the list with the most publications (101) and also with the highest value of h-index (22), followed by Chinese Academy of Sciences (78) and Amirkabir University of Technology (63) with an h-index of 14 and 16, respectively. Among all 20 institutions, there are 9 institutions in China, but their h-index is lower than average h-index (10.8) except Chinese Academy of Sciences and Ministry of Education China. As the dominant country, the USA only has two institutions, but one of them, United

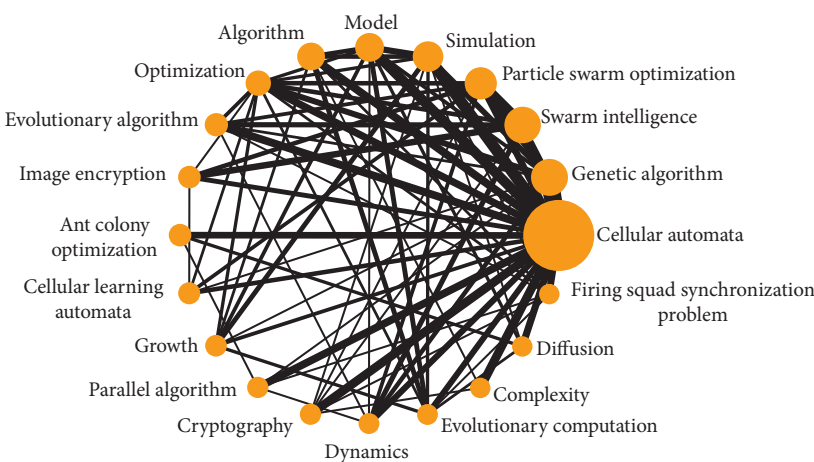

FIgURE 8: The cross-relationship map of the top 20 author keywords in cellular automata algorithm.

States Department of Energy (DOE), has the highest citation times (1757) and the highest ACCP (83.67). The other one, named University of California System, has the second highest h-index (18). It indicts that the USA also shows dominant influence in institutions. Compared with the influence of American research institutions, Chinese counterparts need more efforts to improve qualities of their research work and global influences in this field.

3.6. Contribution of Leading Authors in Cellular Automata Algorithm. Table 5 shows the top 20 most productive authors based on the number of publications. Meybodi, the most prolific author, comes from Amirkabir University of Technology, Iran, who published 41 (1.32\%) articles in cellular automata algorithm field. He was then followed by Sirakoulis $(36,1.16 \%)$ and Umeo $(27,0.83 \%)$, who come from Greece and Japan, respectively.

It is shown in Table 5, Sirakoulis, Karafyllidis, and Thanailakis come from the same institution which leads the list of top 20 productive institutions, named Democritus University of Thrace. Their h-index is 22,19 , and 22, respectively, which are almost the same as average h-index 
TABLE 4: The top 20 most productive institutions of publications during 1984-2020.

\begin{tabular}{lccccccc}
\hline Rank & Institutions & TA & TC & ACCP & TPR\% & h-Index & Country \\
\hline 1 & Democritus University of Thrace & 101 & 1506 & 14.91 & 3.26 & 22 & Greece \\
2 & Chinese Academy of Sciences & 78 & 615 & 7.88 & 2.52 & 14 & China \\
3 & Amirkabir University of Technology & 63 & 743 & 11.79 & 2.03 & 16 & Iran \\
9 & Centre National de la Recherche Scientifique (CNRS) & 60 & 645 & 10.75 & 1.94 & 13 & France \\
4 & Ministry of Education China & 38 & 1035 & 27.24 & 1.23 & 15 & China \\
8 & Ecole Polytechnique Federale de Lausanne & 37 & 1542 & 41.68 & 1.19 & 15 & Switzerland \\
5 & Wuhan University & 35 & 205 & 5.86 & 1.13 & 7 & China \\
6 & University of California System & 32 & 1205 & 37.66 & 1.03 & 18 & USA \\
7 & Tsinghua University & 31 & 303 & 9.77 & 1.00 & 8 & China \\
10 & Sichuan University & 27 & 596 & 22.07 & 0.87 & 5 & China \\
11 & Islamic Azad University & 26 & 185 & 7.12 & 0.84 & 10 & Iran \\
12 & Tsaka Electro-Communication University & 24 & 201 & 8.38 & 0.77 & 10 & Japan \\
13 & Tongji University & 24 & 180 & 7.50 & 0.77 & 6 & China \\
14 & University of Sheffield & 23 & 296 & 12.87 & 0.74 & 9 & UK \\
15 & Shanghai Jiao Tong University & 22 & 447 & 20.32 & 0.71 & 6 & China \\
16 & Osaka University & 22 & 223 & 10.14 & 0.71 & 5 & Japan \\
19 & United States Department of Energy (DOE) & 21 & 1757 & 83.67 & 0.68 & 13 \\
17 & Pukyong National University & 21 & 189 & 9.00 & 0.68 & 9 & SSA \\
18 & Harbin Institute of Technology & 21 & 148 & 7.05 & 0.68 & 7 & South Korea \\
20 & Southwest Jiaotong University & 20 & 222 & 11.10 & 0.65 & China \\
\hline
\end{tabular}

TA: total articles; TC: total citations; ACPP: average citations per publication; TPR\%: the percentage of articles of institutions in total publications.

TABLE 5: Contribution of the top 20 authors in cellular automata algorithm research.

\begin{tabular}{lccccccc}
\hline Rank & Author & TA & TC & ACPP & TPR\% & h-Index & Institute, country/regions \\
\hline 1 & Meybodi, Mohammad Reza & 41 & 805 & 19.63 & 1.32 & 30 & Amirkabir University of Technology, Iran \\
2 & Sirakoulis, Georgios Ch. & 36 & 839 & 23.31 & 1.16 & 22 & Democritus University of Thrace, Greece \\
3 & Umeo, Hiroshi & 27 & 222 & 8.22 & 0.87 & 12 & Osaka Electro-Communication University, Japan \\
4 & Karafyllidis, Ioannis G. & 25 & 891 & 35.64 & 0.81 & 19 & Democritus University of Thrace, Greece \\
5 & Li, Xiaowei & 23 & 150 & 6.52 & 0.74 & 11 & Sichuan University, China \\
6 & Li, Xia & 22 & 1083 & 49.23 & 0.71 & 48 & East China Normal University, China \\
7 & Thanailakis, Antonios T. & 19 & 952 & 50.11 & 0.61 & 22 & Democritus University of Thrace, Greece \\
8 & Kim, Seoktae & 17 & 166 & 9.76 & 0.55 & 9 & Sichuan University, China \\
9 & Spataro, William & 15 & 372 & 24.80 & 0.48 & 22 & Università della Calabria, Italy \\
10 & D’Ambrosio, Donato & 15 & 402 & 26.80 & 0.48 & 18 & Università della Calabria, Italy \\
11 & Liu, Xiaoping & 15 & 303 & 20.20 & 0.48 & 36 & Sun Yat-sen University, China \\
12 & Feng, Yongjiu & 15 & 195 & 13.00 & 0.48 & 16 & Tongji University, China \\
13 & Seredyński, Franciszek & 15 & 231 & 15.40 & 0.48 & 12 & Uniwersytet Kardynala Stefana Wyszynskiego \\
14 & Kutlu, Bülent & 15 & 116 & 7.73 & 0.48 & 10 & w Warszawie, Poland \\
15 & Adamatzky, Andrew & 13 & 202 & 15.54 & 0.42 & 35 & University of the West of England, United Kingdom \\
16 & Tomassini, Marco & 13 & 323 & 24.85 & 0.42 & 31 & Université de Lausanne (UNIL), Switzerland \\
17 & Sipper, Moshe & 13 & 281 & 21.62 & 0.42 & 20 & University of Pennsylvania, USA \\
18 & Afshar, M. H. & 13 & 97 & 7.46 & 0.42 & 22 & Iran University of Science and Technology, Iran \\
19 & Di Gregorio, Salvatore & 12 & 387 & 32.25 & 0.39 & 22 & ISAC-CNR, Italy \\
20 & Billings, Steve A. & 12 & 167 & 13.92 & 0.39 & 22 & University of Sheffield, United Kingdom \\
\hline
\end{tabular}

(21.95). Particularly, Thanailakis, Antonios T. has the highest ACPP (50.11). From that, it can be concluded that there is a strong relationship between the contributions of them and the leading position of Democritus University of Thrace. Apart from that, there are 5 Chinese authors come from 4 different institutions, which are all universities. Li, Xia has the second highest ACPP (49.23) and the highest h-index (48). And the author who has the second highest h-index (36) is Liu, Xiaoping. Interestingly, they have intense relationship who have cooperated and finished 118 articles, not only in field of cellular automata algorithm.

The contribution of the top 20 authors each year during 1984 to 2020 is displayed in Figure 9. Thanailakis, the earliest author among the top 20 productive authors, published his first article related to cellular automata algorithm in 1992 [45]. In this article, he presented a new algorithm based on new, multistate, $2 \mathrm{D}$ cellular automata (CA) architecture to calculate the minimum cost path between a pair of points on 


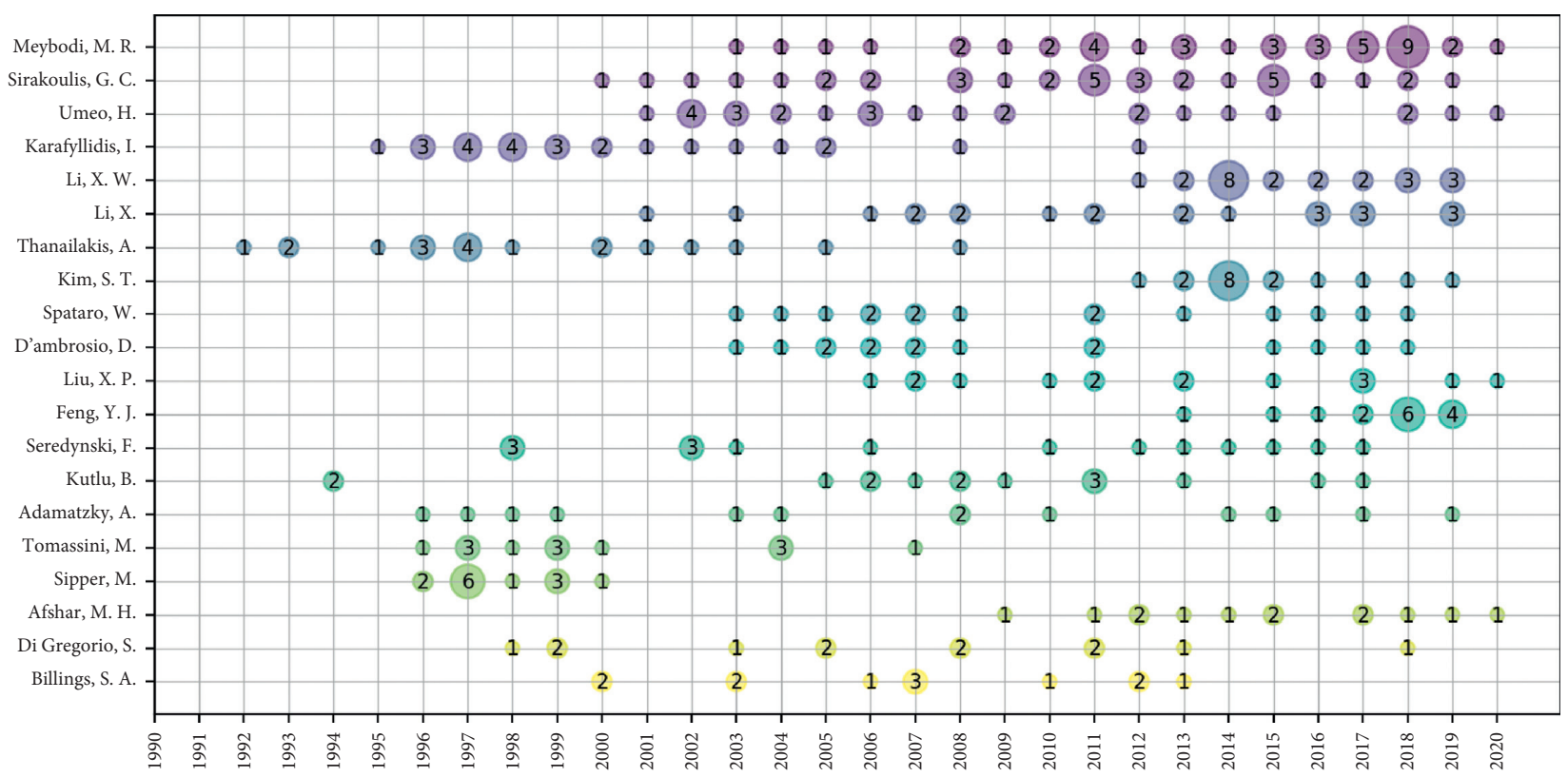

FIGURE 9: The bubble chart of top 20 productive authors in cellular automata algorithm by year.

a binary map. In 1993, Thanailakis published 2 articles, one about improvement of $2 \mathrm{D}$ cellular automata algorithm on the basis of his first paper [46] and the other one is about a new algorithm whose implementation was based on $3 \mathrm{D}$ cellular automata architecture, for the estimation of the minimum cost path between a pair of points in the $3 \mathrm{D}$ space [47]. However, Thanailakis has not published any article related to cellular automata algorithm from 2009; the same situation occurs by Tomassini, Marco and Sipper, Moshe, who are the only authors from the USA.

\section{Research Interests: Production Scheduling Problems in Manufacturing System}

On the basis of analysis on the cellular automata algorithm above, it can be concluded that research on the cellular automata algorithm attracts more and more attention and interest from potential followers and researchers in various kinds of research fields, such as computer science, geography, and environment engineering. Furthermore, the study and applications of cellular automata in manufacturing systems also attract researchers.

Although the words related to "production scheduling" does not belong to the top 20 in the analysis of author keywords, it has been used frequently in the recent 10 years and shows a growth trend, indicating that the topic of study and applications of cellular automata in production scheduling is an inspiring and potential research area. The production scheduling problem was proven to be a NP-hard problem, and researchers used to solve these problems by establishing mathematical programming models and getting the precise optimal solutions by the Branch and Bound Method, linear programming method, and so on or approximate optimal solutions by some intelligent algorithms, such as genetic algorithm, ant colony algorithm, and particle swarm optimization. However, these methods only apply to solve small scale scheduling problems, and the rationality of the mathematical model simplification and the universality of the model abstraction directly affect the application of the model. Thus, how to get an optimal solution of large-scale complex scheduling systems is a new area for researchers to explore.

In the 1980s, "Complex Science" was proposed by the Santa Fe School in the United States. Once it was proposed, it attracted widespread attention around the world. In 1985, Prigogine, the founder of the theory of dissipative structure and the Nobel Prize winner in chemistry, revealed how the material movement changed from disorder to order and from instability and inconsistency to stable coordination. The theory that nonequilibrium is the source of order has raised the problem of self-organization in complex systems. In 1988, Anderson and Arow organized a symposium to propose that economic management can be seen as an evolutionary complex system. Since then, with the deepening of research, the theories of nonlinear, nonequilibrium, mutation, chaos, fractal, and self-organization involved in complex systems have become more and more widely used in the field of economic management. At present, scientific research on complexity and complex systems occupies an increasingly important position and has been praised by some scientists as the "science of the 21st century." The cellular automata (CA) approach, a simple mathematical model, is widely used to analyze complex systems which is discrete in space and time.

To illustrate the development history on the application of cellular automata algorithm in production scheduling in complex manufacturing system, some important details are shown by year in Figure 10. In 1999, Kosturiak and Gregor, from University of Zilina, summarized some discrete events of simulation models for the designs, operations, and continuous improvements of complex manufacturing and production logistics systems and emphasized the simulation 


\begin{tabular}{|c|}
\hline $\begin{array}{l}\text { Kosturiak and Gregor summarized some discrete events of } \\
\text { simulation models for the designs and emphasized the } \\
\text { simulation of enterprise production logistics system } \\
\text { through discrete parameter partition (1999). }\end{array}$ \\
\hline $\begin{array}{c}\text { Qiuhua Tang presented an intelligent cellular scheduling } \\
\text { model for efficient and accurate flexible hybrid operations. } \\
\text { This paper applied agent to cellular automata model to } \\
\text { make it more flexible and intelligent (2007). }\end{array}$ \\
\hline $\begin{array}{l}\text { Zhibin Jiang combined cellular automata model and } \\
\text { genetic algorithm together; the genetic operators were } \\
\text { applied to improve the evolution of cellular automata } \\
\text { model and the speed and accuracy of convergence (2007). }\end{array}$ \\
\hline
\end{tabular}

Abdolzadeh combined cellular automata and a reinforcement learning algorithm for the first time and applied cellular learning automata to solve the job shop scheduling problem (2009).

Antczak, Witkowski used evolving cellular automata for flexible job shop with a makespan criterion and applied data mining to explore the regularities of CA in scheduling (2009).

Yong Chen proposed an improved genetic algorithm to optimize local evolution rules of cellular automata-based job-shop scheduling model (2012).

Oliveira, Gina M.B. proposed a new approach named multigraph coevolutionary learning, in which a population of program graphs is evolved simultaneously with rules population leading to more generalized transition rules (2012).

Yong Chen proposed a new way to solve scheduling problems of polymorphism job shop, based on CAGA (Cellular Automata-Genetic Algorithm) (2014).

Tongtong Lu proposed an asynchronous cellular Genetic Algorithm (acGA). The asynchronous update strategy was applied in traditional cellular genetic algorithm (2014).

Kucharska, E proposed a new approach based on the cellular automata technique for a specific class of scheduling problems with parallel machines and proposed inseparable use of simulation, optimization, and result levels (2016).

Jakub Gasior proposed a decentralized multiagent system working in a critical state at the edge of chaos based on the concept of the sandpile cellular automaton. This model is used to dynamic load balancing and rescheduling in the cloud environment (2016).

Yuqi Yang proposed a hybrid cellular genetic algorithm for flexible job shop scheduling (2018).

Carvalho, Tiago Ismailer studied different probabilistic distributions to be used in the cellular automata model update. The uniform distribution is applied to increase the probability of states that appeared more often in the neighborhood of a cell (2018) solve problems such as enterprise logistics system optimization and complex resource allocation policies (2003).

Zhong Zheng proposed a simulation model of crane scheduling in a workshop based on cellular automata. According to the crane scheduling rules and operating characteristics, the evolution rules of model were abstracted and formulated (2008)

2010

Yong Chen presented a cellular automata-based simulation model of dynamic and flexible scheduling in a large-sized component production workshop. Its scheduling rules included station choosing rules, work piece sequencing rules, and task activating rules (2010).

Tang, Qiuhua proposed a specific cooperative method and adaptive scheduling model based on the theory of cellular automata system modeling for programming mixed-model assembly production operations (2010).

Yong Chen proposed a method of agent-cellular automata modeling for job shop scheduling. He combined the multimaster system and cellular automata and established the physical model and evolution model of Agent-Cellular Automata (2013).

Yong Chen proposed a large-scale 4D scheduling model based on cellular automata. In this paper, a rule-based two-

dimensional spatial scheduling model and a device scheduling model were established based on hierarchical genetic algorithm (2015).

2015

$\mathrm{Hu}$, Wenbin proposed an outer-inner uncertainty fuzzy cellular automata algorithm (OIUFCA) to solve the dynamic uncertain multiproject scheduling problem (DUMPSP) (2015).
2017

Tongtong Lu proposed a new algorithm combined with Bat Algorithm and Cellular Automata (2017).

$\mathrm{Lu}$, Chao proposed a new way to solve the hybrid flowshop scheduling problem (HFSP) which was a multiobjective cellular grey wolf optimizer (MOCGWO) which integrates the merits of cellular automata (CA) for diversification and variable neighborhood search (VNS) (2019).

2018

Carlos Seck-Tuoh-Mora, Juan applied cellular automata model into alternate two phases particle swarm optimization (ATPPSO) to enhance the local search based on a neighborhood for every solution (2019).

Franciszek Seredyński proposed a fully distributed algorithm based on applying Iterated Spatial Prisoner's Dilemma (ISPD) game and a phenomenon of collective behavior of players participating in the game to solve the problem of securityaware scheduling and load balancing in Cloud Computing (CC) systems (2019).

Figure 10: The articles about the field of cellular automata and production scheduling. 
of enterprise production logistics system through discrete parameter partition $[4,48]$.

In 2003, Pasquale, from University Calabria, proposed a cell queue network simulation model to solve problems such as enterprise logistics system optimization and complex resource allocation policies [49]. They were the earliest theories and applications of cellular automata applied in production scheduling systems and provided some theoretical supports for the after researchers.

In 2007, Zhibin Jiang, from Shanghai Jiaotong University, combined cellular automata model and genetic algorithm together; the genetic operators were applied to improve the evolution of cellular automata model and the speed and accuracy of convergence. The scheduling sequences were put into a spatial grid structure of cells, which were distributed over a connected graph to form dynamic populations, and the genetic algorithm was applied to each cell; especially, chromosomes are composed of the order of all processes, and each gene represents a process. And the influence of good cell only diffused around its neighborhood to avoid premature [50].

In the same year, Tang, from Wuhan University of Science and Technology, presented an intelligent cellular scheduling model for efficient and accurate flexible hybrid operations. This paper applied agent to cellular automata model to make it more flexible and intelligent. The mechanism of the model correctly describes the micro- and ultimate requirements of flexible scheduling itself, condenses the system structure, and reduces the computational complexity of complex problems [51]. In fact, the use of AgentBased Model (ABM) is more frequent than before, and that is one of the reasons why the cellular automata algorithm is one of the most popular algorithms in the world. In 2016, Gasior, from Polish Academy of Sciences, proposed a decentralized multiagent system working in a critical state at the edge of chaos based on the concept of the sandpile cellular automaton. This model inherits the benefits of both static and dynamics scheduling strategies and is used to dynamic load balancing and rescheduling in the Cloud environment, which gets better performance than other scheduling strategies in dynamic environments [52]. In 2019, Seredyński proposed a fully distributed algorithm based on applying Iterated Spatial Prisoner's Dilemma (ISPD) game and a phenomenon of collective behavior of players participating in the game to solve the problem of security-aware scheduling and load balancing in Cloud Computing (CC) systems. The essential of this model is to use a concept of the second-order CA and introduce some specific mechanisms of interaction between agents [53].

Above all, it can be concluded that two main applications of cellular automata algorithm in production scheduling are as follows: one is to establish a simulation model of complex scheduling systems by cellular automata structure and evolve the model by special rules; the other is to improve intelligent scheduling algorithm by the cellular neighborhood mechanism.

Consequently, almost all researches were based on these two applications. Zheng, from Chongqing University, proposed a simulation model of crane scheduling in a workshop based on cellular automata in 2008 [54]. In that case, the object of research is crane scheduling. According to the crane scheduling rules and operating characteristics, the evolution rules of model were abstracted and formulated. Through that, this paper realized the use of relatively simple local interactions to reflect the complex macro behaviors of crane operation and proved that the simulation method of crane scheduling based on cellular automata was feasible and effective.

In 2009, Witkowski, from Warsaw University Technology, used evolving cellular automata for flexible job shop with a makespan criterion and applied data mining to explore the regularities of CA in scheduling [55]. Abdolzadeh, from Islamic Azad University, combined cellular automata and a reinforcement learning algorithm for the first time and applied cellular learning automata to solve the job-shop scheduling problem: by generating actions based on received responses from the problem environment, the appropriate position for operation of jobs was chosen in execution sequence [56]. It should be noted that Chen's group made a relatively significant contribution in this field with 7 publications.

In 2010, Yong Chen, from Zhejiang University of Technology, presented a cellular automata-based simulation model of dynamic and flexible scheduling in a large-sized component production workshop [57]. The scheduling system was divided into 4 parts: work station, buffer, workpiece, and scheduling rules. The work station and buffer were viewed as fixed grid nodes, the workpiece as moving particles, and scheduling rules as the local self-evolution rules which included station choosing rules, workpiece sequencing rules, and task activating rules. It was verified that simulation modeling based on cellular automata is an effective method dealing with the dynamic and flexible scheduling in a large-sized component production workshop.

On the basis of the above research, an improved genetic algorithm was used to optimize local evolution rules of cellular automata-based job-shop scheduling model in 2012 [58]. In addition, a method of agent-cellular automata modeling was proposed for job-shop scheduling in 2013 [59]. In this paper, Yong Chen combined the multimaster system and cellular automata and established the physical model and evolution model of agent-cellular automata. The evolution rules, such as First-In-First-Out (FIFO) and FirstCome-First-Serve (FCFS), were applied in this model whose feasibility was certified by swarm simulation.

In 2014, a new way to solve scheduling problems of polymorphism job shop was proposed, based on CA-GA (Cellular Automata-Genetic Algorithm) model, by Chen. Apart from that, original scheduling and rescheduling were simulated according to equipment failures and order insertions which certified the superiority of this way [60]. Next year, Chen proposed a large-scale 4D scheduling model based on cellular automata [61]. In this paper, a rule-based two-dimensional spatial scheduling model and a device scheduling model were established based on hierarchical genetic algorithm on the three-dimensional partition layer, and cells formed the evolution of a dynamic scheduling 
system through the interaction of self-organizing evolution rules.

Except Chen group, the Lu group, from China's Three Gorges University, had also paid much attention to the applications of cellular automata in scheduling, leading to 5 publications. Different from Chen's group, they mainly focused on the improvement of intelligent algorithm by cellular automata. In 2014, an asynchronous cellular Genetic Algorithm (acGA) was proposed by this group. The asynchronous update strategy, which meant that the individual offspring were generated and updated one by one in a specific order during the algorithm iteration process, was applied in traditional cellular genetic algorithm. As a result, new algorithm showed higher search efficiency, faster convergence speed, and better algorithm stability [62]. In 2017, a new algorithm combined with Bat Algorithm and Cellular Automata was proposed. Cellular automata model strengthened the flow of information within the population of bat algorithm [63]. Next year, hybrid cellular genetic algorithm was proposed by this group for flexible job-shop scheduling [64].

In 2019, Lu, Chao, from China University of Geosciences, proposed a new way to solve the hybrid flowshop scheduling problem (HFSP) which was a multiobjective cellular grey wolf optimizer (MOCGWO) which integrates the merits of cellular automata (CA) for diversification and variable neighborhood search (VNS). Apart from that, the effectiveness of the cellular automata is tested in this paper. In CA, each subpopulation independently evolves its search progress in its own neighborhood. As a result, the optimizer can search for unknown areas of the search space in a parallel search way. Thus, it is indicated that the search diversity is improved by CA model [65]. The same year, Carlos SeckTuoh-Mora, Juan, from Universidad Autonoma del Estado de Hidalgo, applied cellular automata model into alternate two-phase particle swarm optimization (ATPPSO) to enhance the local search based on a neighborhood for every solution [66].

Other contributors in the field of cellular automata and scheduling are shown in Figure 10 [67-71].

\section{Conclusions}

The focal point of interest in this study was to conduct a bibliometric analysis of global research in the cellular automata algorithm and its new and promising application in manufacturing scheduling systems. There is no doubt that it is a rapidly growing topic, supported by our analysis of global contributions, countries or regions productivity, related journals, prolific authors, new research areas, and so on, from 3086 related articles and reviews, published during the period of 1984-2020. The cellular automata algorithm has been developed over 30 years and received more scientific attention in 1990, reaching its explosive growth in 2017 because a trend that combining cellular automata model and intelligent algorithms was rising.

The growth rate of publications related to it has been relatively stable. This bibliometric analysis has confirmed that the USA and China are the dominant countries in terms of the volume of their contributions, followed by Japan and India. As for cooperation, the USA is the most active country that has cooperated with other 47 countries and regions. According to the analysis of research area, China and the USA are still in dominant position, occupying "the most active country" of 19 areas. Apart from that, there are three main areas related to cellular automata: they are "Computer Science," "Mathematics," and "Physics." The areas can be divided clearly based on the analysis of author keywords on cellular automata algorithm. The keywords, such as "genetic algorithm," "ant colony optimization," and "evolutionary computation," show an intense relationship with intelligent algorithms and cellular automata. Particularly, "image encryption" and "cryptography," which belong to cryptography area, also indicate the wide application of cellular automata.

As for institutions and authors, Democritus University of Thrace, from Greece, is the most productive institution and also had the highest h-index. And there are three leading authors from that institution. China has 9 institutions there and 6 of these are universities. The authors who have the first and second highest $\mathrm{h}$-index are from China; their names are Li, Xia and Liu, Xiaoping with 48 and 36 h-index, respectively. For journals, Journal of Cellular Automata is the most comprehensive source of cellular automata algorithm publications, followed by Cellular Automata, Proceedings.

Finally, on the analysis of the reviews on the cellular automata algorithm, we find that the application of cellular automata algorithm in production scheduling is a new and promising research area, in which researchers could apply the cellular automata modeling theory to the complex scheduling system to demonstrate its internal operations or apply the neighborhood mechanism to the improvement of intelligent scheduling algorithm. In the meanwhile, it is found that the cellular automata algorithms work well with the use of Agent-Based Model (ABM).

\section{Conflicts of Interest}

The authors declare that they have no conflicts of interest.

\section{Acknowledgments}

The authors are grateful for the financial support partly from the Natural Science Foundation of China under Grants nos. 71871203, 51305400, and L1924063, Zhejiang Provincial Natural Science Foundation of China under Grants nos. LY18G010017 and GB17041020029, Foundation of Zhejiang Educational Committee nos. Y201330222 and Y201840056, and Visiting Scholar Specialty Development Foundation no. FX2016036.

\section{References}

[1] J. V. Neumann and A. W. Burks, Theory of Self-Reproducing Automata, University of Illinois Press, Champaign, IL, USA, 1966.

[2] S. Wolfram, "Computation theory of cellular automata," Communications in Mathematical Physics, vol. 96, no. 1, pp. 15-57, 1984. 
[3] S. Wolfram, "Cellular automata supercomputing," Frontiers of Massively Parallel Scientific Computation, Washington, DC, USA, pp. 87-95, 1987.

[4] J. Košturiak and M. Gregor, "Simulation in production system life cycle," Computers in Industry, vol. 38, no. 2, pp. 159-172, 1999.

[5] N. Strange, H. Meilby, and B. J. Thorsen, "Optimization of land use in afforestation areas using evolutionary self-organization," Forest Science, vol. 48, no. 3, pp. 543-555, 2002.

[6] D. Wu, J. Liu, S. Wang, and R. Wang, "Simulating urban expansion by coupling a stochastic cellular automata model and socioeconomic indicators," Stochastic Environmental Research and Risk Assessment, vol. 24, no. 2, pp. 235-245, 2009.

[7] Q.-X. Liu, R.-H. Wang, Z. Jin, J. van de Koppel, and D. Alonso, "Spatial self-organization in a multi-strain host-pathogen system," Journal of Statistical Mechanics: Theory and Experiment, vol. 2010, no. 5, Article ID P05017, 2010.

[8] Y. Liu and Y. J. Feng, "Simulating the impact of economic and environmental strategies on future urban growth scenarios in ningbo, China," Sustainability, vol. 8, no. 10, p. 16, 2016.

[9] A. Nowak, M. Kus, J. Urbaniak, and T. Zarycki, "Simulating the coordination of individual economic decisions," Physica A, vol. 287, no. 3-4, pp. 613-630, 2000.

[10] H. B. Sieburg, J. A. McCutchan, O. K. Clay, L. Cabalerro, and J. J. Ostlund, "Simulation of HIV-infection in artificial immune-systems," Physica D, vol. 45, no. 1-3, pp. 208-227, 1990.

[11] G. B. Ermentrout and L. Edelstein-Keshet, "Cellular automata approaches to biological modeling," Journal Of Theoretical Biology, vol. 160, no. 1, pp. 97-133, 1993.

[12] S. H. White, A. M. del Rey, and G. R. Sánchez, "Modeling epidemics using cellular automata," Applied Mathematics And Computation, vol. 186, no. 1, pp. 193-202, 2007.

[13] J. Peter and W. Semmler, "Integrating kinetic models for simulating tumor growth in Monte Carlo simulation of ECT systems," Ieee Transactions on Nuclear Science, vol. 51, no. 5, pp. 2628-2633, 2004.

[14] P. S. P. Silveira and E. Massad, "Modeling and simulating morphological evolution in an artificial life environment," Computers And Biomedical Research, vol. 31, no. 1, pp. 1-17, 1998.

[15] B. Ostendorf, D. W. Hilbert, and M. S. Hopkins, "The effect of climate change on tropical rainforest vegetation pattern," Ecological Modelling, vol. 145, no. 2-3, pp. 211-224, 2001.

[16] F. J. Mullany, L. T. W. Ho, L. G. Samuel, and H. Claussen, "Self-deployment, self-configuration: critical future paradigms for wireless access networks," in Autonomic Communication, M. Smirnov, Ed., vol. 3457, pp. 58-68, Springer-Verlag, Berlin, Germany, 2005.

[17] A. Garcia, F. Luís Cônsoli, W. A. C. Godoy, and C. P. Ferreira, "A mathematical approach to simulate spatio-temporal patterns of an insect-pest, the corn rootworm Diabrotica speciosa (Coleoptera: chrysomelidae) in intercropping systems," Landscape Ecology, vol. 29, no. 9, pp. 1531-1540, 2014.

[18] M. K. Firozjaei, M. Kiavarz, S. K. Alavipanah, T. Lakes, and S. Qureshi, "Monitoring and forecasting heat island intensity through multi-temporal image analysis and cellular automata-Markov chain modelling: a case of Babol city, Iran," Ecological Indicators, vol. 91, pp. 155-170, 2018.

[19] C. G. Langton, "Computation at the edge of chaos-phasetransitions and emergent computation," Physica D, vol. 42, no. 1-3, pp. 12-37, 1990.

[20] C. P. H. Mulder and R. W. Ruess, "Long-term effects of changes in goose grazing intensity on arrowgrass populations: a spatially explicit model," Journal Of Ecology, vol. 89, no. 3, pp. 406-417, 2001.
[21] G. Spezzano and D. Talia, "Designing parallel models of soil contamination by the CARPET language," Future Generation Computer Systems-The International Journal Of Grid Computing And Escience, vol. 13, no. 4-5, pp. 291-302, 1998.

[22] S. Di Gregorio and R. Serra, "An empirical method for modelling and simulating some complex macroscopic phenomena by cellular automata," Future Generation Computer Systems, vol. 16, no. 2-3, pp. 259-271, 1999.

[23] D. D'Ambrosio, W. Spataro, and G. Iovine, "Parallel genetic algorithms for optimising cellular automata models of natural complex phenomena: an application to debris flows," Computers \& Geosciences, vol. 32, no. 7, pp. 861-875, 2006.

[24] Q. Guan, X. Shi, M. Huang, and C. Lai, "A hybrid parallel cellular automata model for urban growth simulation over GPU/CPU heterogeneous architectures," International Journal Of Geographical Information Science, vol. 30, no. 3, pp. 494-514, 2016.

[25] J. Das, S. M. Alam, and S. Bhanja, "Low power magnetic quantum cellular automata realization using magnetic multilayer structures," Ieee Journal on Emerging And Selected Topics In Circuits And Systems, vol. 1, no. 3, pp. 267-276, 2011.

[26] E. M. Carreno, R. M. Rocha, and A. Padilha-Feltrin, "A cellular automaton approach to spatial electric load forecasting," Ieee Transactions on Power Systems, vol. 26, no. 2, pp. 532-540, 2011.

[27] M. S. Salehi and S. Serajzadeh, "Simulation of static recrystallization in non-isothermal annealing using a coupled cellular automata and finite element model," Computational Materials Science, vol. 53, no. 1, pp. 145-152, 2012.

[28] A. Berezovski, "Simulation of non-linearheat conduction by means of thermodynamics-based algorithm," International Journal of Numerical Methods for Heat \& Fluid Flow, vol. 7, no. 7, pp. 711-721, 1997.

[29] O. Pelliccioni, M. Cerrolaza, and R. Surós, "A biofluid dynamic computer code using the general lattice Boltzmann equation," Advances In Engineering Software, vol. 39, no. 7, pp. 593-611, 2008.

[30] J. Yang, L. Guo, and X. Zhang, "A numerical simulation of pool boiling using CAS model," International Journal Of Heat And Mass Transfer, vol. 46, no. 25, pp. 4789-4797, 2003.

[31] W. Zhao, T. H. Beach, and Y. Rezgui, "Optimization of potable water distribution and wastewater collection networks: a systematic review and future research directions," IEEE Transactions on Systems, Man, and Cybernetics: Systems, vol. 46, no. 5, pp. 659-681, 2016.

[32] H. S. Chen, Z. Zheng, Z. W. Chen, and X. T. T. Bi, "A lattice gas automata model for the coupled heat transfer and chemical reaction of gas flow around and through a porous circular cylinder," Entropy, vol. 18, no. 1, p. 16, 2016.

[33] G. Bao, H. Fang, L. Chen et al., "Soft robotics: academic insights and perspectives through bibliometric analysis," Soft Robotics, vol. 5, no. 3, pp. 229-241, 2018.

[34] Y. Chen, "A bibliometric analysis for the research on laser processing based on Web of Science," Journal Of Laser Applications, vol. 32, no. 2, p. 16, 2020.

[35] L. I. Meho and K. Yang, "Impact of data sources on citation counts and rankings of LIS faculty: Web of science versus scopus and google scholar," Journal Of the American Society for Information Science And Technology, vol. 58, no. 13, pp. 2105-2125, 2007.

[36] F. Franceschini and D. A. Maisano, "Analysis of the Hirsch index's operational properties," European Journal Of Operational Research, vol. 203, no. 2, pp. 494-504, 2010. 
[37] S. Geng, Y. Wang, J. Zuo, Z. Zhou, H. Du, and G. Mao, "Building life cycle assessment research: a review by bibliometric analysis," Renewable and Sustainable Energy Reviews, vol. 76, pp. 176-184, 2017.

[38] J. E. Hirsch, “An index to quantify an individual's scientific research output that takes into account the effect of multiple coauthorship," Scientometrics, vol. 85, no. 3, pp. 741-754, 2010.

[39] S. H. Zyoud and D. Fuchs-Hanusch, "A bibliometric-based survey on AHP and TOPSIS techniques," Expert Systems with Applications, vol. 78, pp. 158-181, 2017.

[40] J. E. Hirsch, "An index to quantify an individual's scientific research output," Proceedings of the National Academy of Sciences, vol. 102, no. 46, pp. 16569-16572, 2005.

[41] L. Egghe, "An improvement of the H-index: the G-index," ISSI Newsletter, vol. 2, 2006.

[42] L. I. Meho and Y. Rogers, "Citation counting, citation ranking, andh-index of human-computer interaction researchers: a comparison of Scopus and Web of Science," Journal Of the American Society for Information Science And Technology, vol. 59, no. 11, pp. 1711-1726, 2008.

[43] L. Wang, L. Zhao, G. Mao, J. Zuo, and H. Du, "Way to accomplish low carbon development transformation: a bibliometric analysis during 1995-2014," Renewable and Sustainable Energy Reviews, vol. 68, pp. 57-69, 2017.

[44] J. Tan, H.-Z. Fu, and Y.-S. Ho, "A bibliometric analysis of research on proteomics in Science Citation Index Expanded," Scientometrics, vol. 98, no. 2, pp. 1473-1490, 2014.

[45] P. Tzionas, P. Tsalides, and A. Thanailakis, "Cellular automata based minimum cost path estimation on binary maps," Electronics Letters, vol. 28, no. 17, pp. 1653-1654, 1992.

[46] P. Tzionas, P. Tsalides, and A. Thanailakis, "2-Dimensional minimum cost path planning using a cellular automaton architecture," Integration, vol. 16, no. 2, pp. 179-194, 1993.

[47] P. G. Tzionas, P. Tsalides, and A. Thanailakis, "New algorithm for three-dimensional minimum cost path planning and its VLSI implementation by means of a three-dimensional cellular automata architecture," Optical Engineering, vol. 32, no. 11, pp. 2974-2985, 1993.

[48] D. R. Jansen, A. v. Weert, A. J. M. Beulens, and R. B. M. Huirne, "Simulation model of multi-compartment distribution in the catering supply chain," European Journal Of Operational Research, vol. 133, no. 1, pp. 210-224, 2001.

[49] P. Legato and R. M. Mazza, "Berth planning and resources optimisation at a container terminal via discrete event simulation," European Journal of Operational Research, vol. 133, no. 3, pp. 537-547, 2001.

[50] F. Liang and Z. B. Jiang, "Adaptive job shop scheduling based on cellular automata model," Journal of Shanghai Jiaotong University, vol. 41, no. 9, pp. 1497-1500, 2007.

[51] Q. Tang, Z. Xi, P. Chen, and Y. Yan, "Intelligent cellular scheduling method for high efficiency and punctuality in mixed model assembly line," Journal of Wuhan University of Science and Technology: Natural Science Edition, vol. 4, pp. 379-383, 2007.

[52] J. Gasior and F. Seredynski, "A Sandpile cellular automatabased scheduler and load balancer," Journal of Computational Science, vol. 21, pp. 460-468, 2017.

[53] J. Gąsior and F. Seredyński, "Security-aware distributed job scheduling in Cloud computing systems: a game-theoretic cellular automata-based approach," in Proceedings of the 19th International Conference on Computational Science, vol. 11537, LNCS, Faro, Portugal, pp. 449-462, June 2019.
[54] Q. Tang, Z. Xi, P. Chen, and Y. Yan, "Research on scheduling strategy for high efficiency and punctuality in mixed model assembly line," China Mechanical Engineering, vol. 18, no. 9, pp. 1108-1111, 2007.

[55] A. Antczak, P. Antczak, and T. Witkowski, "Using of evolving cellular automata for flexible job shop with makespan criterion," in Proceedings of the 2009 IEEE International Workshop on Intelligent Data Acquisition and Advanced Computing Systems: Technology and Applications, pp. 297-302, Rende, Italy, September 2009.

[56] M. Abdolzadeh and H. Rashidi, "Solving job shop scheduling problem using cellular learning automata," in Proceedings of the 2009 Third Uksim European Symposium on Computer Modeling and Simulation, D. AlDabass, S. Katsikas, I. Koukos, A. Abraham, and R. Zobel, Eds., pp. 49-54, IEEE, Athens, Greece, November 2009.

[57] Y. Chen, X. Ruan, and J. Lu, "Simulation modeling of dynamic \& flexible scheduling about large-sized component production workshop based on cellular automata," China Mechanical Engineering, vol. 21, no. 21, pp. 2603-2609, 2010.

[58] Y. Chen, X. Ruan, J. Lu, and Y. Wang, "Flexible job-shop scheduling algorithm of large parts based on cellular automata and improved GA," China Mechanical Engineering, vol. 23, no. 2, pp. 177-184+109, 2012.

[59] J. Zhu, Y. Chen, and J. Lu, "ACA modeling on shop job scheduling of multi-variety and multi-process manufacturing company," Light Industry Machinery, vol. 31, no. 3, pp. 99-103+107, 2013.

[60] Y. Chen, X. Yang, C. Wang, and Y. Wang, "4D Scheduling model for large-scale equipment manufacturing based on cellular automata," Journal of Zhejiang University of Technology, vol. 43, no. 02, pp. 168-174, 2015.

[61] Y. Chen, Y. Pan, Y. Wang, and J. Lu, "Research on modeling of robust scheduling for polymorphism job shop based on cellular automata and genetic algorithm," Journal of Zhejiang University of Technology, vol. 42, no. 2, pp. 124-131+141, 2014.

[62] T. Lu, F. Hu, and Y. Zhang, "An asynchronous cellular genetic algorithm for job shop scheduling problem," Modular Machine Tool and Automatic Manufacturing Technique, vol. 8, pp. 147-151, 2014.

[63] T. Lu, Z. Yu, and X. Zheng, "Dual-gantry placement machine scheduling based on cellular bat algorithm," Modern Manufacturing Engineering, vol. 9, pp. 22-28+101, 2017.

[64] Y. Yang, Y. Zhang, G. Zhang, and T. Lu, "Study on flexible Job Shop scheduling problem based on Hybrid Cellular genetic algorithm," Journal of Three Gorges University, vol. 40, no. 1, pp. 86-91, 2018.

[65] C. Lu, L. Gao, Q. Pan, X. Li, and J. Zheng, "A multi-objective cellular grey wolf optimizer for hybrid flowshop scheduling problem considering noise pollution," Applied Soft Computing, vol. 75, pp. 728-749, 2019.

[66] J. C. Seck-Tuoh-Mora, J. Medina-Marin, E. S. MartinezGomez, E. S. Hernandez-Gress, N. Hernandez-Romero, and V. Volpi-Leon, "Cellular particle swarm optimization with a simple adaptive local search strategy for the permutation flow shop scheduling problem," Archives Of Control Sciences, vol. 29, no. 2, pp. 205-226, 2019.

[67] Q. Tang, Y. Yan, Z. Xi, and P. Chen, "Research on cellular automata system model for adaptive scheduling mixed assembly production with high efficiency and precision," Advances in Systems Science and Applications, vol. 10, no. 3, pp. 554-562, 2010.

[68] G. M. B. Oliveira and P. M. Vidica, "A coevolutionary approach to cellular automata-based task scheduling," in 
Cellular Automata, Acri, G. C. Sirakoulis and S. Bandini, Eds., vol. 7495, pp. 111-120, Springer-Verlag, Berlin, Germany, 2012.

[69] W. Hu, H. Wang, C. Peng, H. Wang, H. Liang, and B. Du, “An outer-inner fuzzy cellular automata algorithm for dynamic uncertainty multi-project scheduling problem," Soft Computing, vol. 19, no. 8, pp. 2111-2132, 2015.

[70] E. Kucharska, K. Grobler-Dębska, K. Raczka, and L. Dutkiewicz, "Cellular Automata approach for parallel machine scheduling problem," Simulation, vol. 92, no. 2, pp. 165-178, 2016.

[71] T. I. Carvalho and G. M. B. Oliveira, "SSCS-lambda: a cellular automata-based scheduler with stochastic update based on the neighbourhood states," in Proceedings of the 2018 IEEE 30th International Conference on Tools with Artificial Intelligence, pp. 452-457, IEEE, Volos, Greece, November 2018. 